\title{
Nanosized $\mathrm{MoO}_{3}$ as a reusable heterogeneous catalyst for the synthesis of 2,6-bis(benzylidene)cyclohexanones
}

\author{
Nitin R. Dighore, Priyanka L. Anandgaonker, Suresh T. Gaikwad, Anjali S. Rajbhoj* \\ Department of Chemistry, Dr. Babasaheb Ambedkar Marathwada University, Aurangabad - 431004 (M.S.), India
}

\begin{abstract}
Crystalline $\mathrm{MoO}_{3}$ nanoparticles were obtained by electrochemical synthesis process using tetrapropylammonium bromide as a stabilizer and structure-directing agent in $\mathrm{ACN}$ :THF(4:1) solvent. Formation of $\mathrm{MoO}_{3}$ nanoparticles took place at a constant supply current of $14 \mathrm{~mA} / \mathrm{cm}^{2}$. These synthesized $\mathrm{MoO}_{3}$ nanoparticles were characterized by UV-Vis spectroscopy, FT-IR spectroscopy, powder X-ray diffraction (XRD), scanning electron microscopy (SEM). So prepared $\mathrm{MoO}_{3}$ nanoparticles were used as a heterogeneous catalyst for the synthesis of 2,6-bis(benzylidene)cyclohexanone derivatives. This protocol offers several advantages, such as simple work-up procedure, recyclability of the catalyst, excellent product yield in a short reaction time and purification of products with a non-chromatographic method.
\end{abstract}

Keywords: electrochemical synthesis; $\mathrm{MoO}_{3}$ nanoparticles; heterogeneous catalyst; 2,6-bis(benzylidene)cyclohexanone

(C) Wroclaw University of Technology.

\section{Introduction}

The $\alpha, \alpha^{\prime}$-unsaturated ketones have been attracting much attention particularly the $\alpha, \alpha^{\prime}$ unsaturated derivatives of cyclohexanone, such as 2,6-bis(benzylidene)cyclohexanone [1], not only due to their intriguing biological activities, such as antiangiogenic [2], cytotoxic [3], cholesterollowering activity [4], but also their potential for nonlinear optical materials [5]. Arylidene cycloalkanones are also useful intermediates for synthesis of bioactive pyrimidine [6], perfumes [7], bis-spiroisoxazolines [8], liquid crystalline polymers [9] and in pharmaceutical applications, especially as HIV-1 integrase inhibitors [10].

Owing to the importance of these compounds, various methods for synthesis of this type of compound have been developed. The typical methods for the preparation of 2,6bis(benzylidene)cyclohexanone generally involve cross-aldol condensation of cyclohexanone with aldehydes in presence of strong acids or bases [11], however, the acid or base catalyzed reactions result in low yield of product due to reverse and side

*E-mail: anjali.rajbhoj@gmail.com reactions [12]. Coordination complexes with a variety of metals have been introduced to replace acid or base, but no satisfactory effect on the yield of the product has been achieved in most cases [13]. Continuing efforts to find a new catalyst resulted in the introduction of various reagents, such as $\mathrm{RuCl}_{3}$ [14], $\mathrm{KF} / \mathrm{Al}_{2} \mathrm{O}_{3}$ [15], $\mathrm{KOH}$ [16], $\mathrm{NaOH}$ [17], I ${ }_{2}$ [18], SSA [19], $\mathrm{Yb}(\mathrm{OTf})_{3}$ [20], $\mathrm{Cu}(\mathrm{OTf})_{2}$ [21], $\quad \mathrm{CH}_{3} \mathrm{CO}_{2} \mathrm{Na} / \mathrm{CH}_{3} \mathrm{CO}_{2} \mathrm{H}$ [22], PEG/AlCl ${ }_{3}$ [23] and $\mathrm{Fe}_{2} \mathrm{O}_{3}$ nanoparticles [24]. The other synthetic methods for preparation of these compounds involve microwave radiation [25] and ultrasound irradiation [26]. However, these methods suffer from one or more disadvantages, such as the use of toxic organic solvents or toxic catalyst and, in many cases, after the completion of the reaction, the catalyst system cannot be recycled. Considering the importance of the preparation of 2,6-bis(benzylidene)cyclohexanone and disadvantages of the currently reported methods, it is important to exploit a simple, efficient and clean procedure for the synthesis of this compound without using hazardous solvents, using less toxic, inexpensive and reusable catalysts.

Nanoparticles have been successfully used to enhance the immobilization and activity of 
a catalyst as the nanocrystalline metal oxide or metal particles have a large surface to volume ratio and increased surface reactivity as compared to that of the bulk material. Molybdenum oxide is a potential material because of its wide range of stoichiometry and interesting behavior, which includes structural [27], chemical [28], electrical and optical [29] properties. $\mathrm{MoO}_{3}$ has received considerable attention in many technological applications, such as erasable optical storage media, optical switching coatings, high density memory devices, gas and chemical sensors [30] catalysis [31, 32] photography, future display materials [33], energy efficient window technology, photochromic and electrochromic devices [34].

In the framework of our studies on electrochemical synthesis of nanoparticles, characterization and their applications in catalytic organic reactions [35-37], we would like to report herein an efficient protocol for aldol condensation of cyclohexanone with various aromatic aldehydes using $\mathrm{MoO}_{3}$ NPs as catalysts.

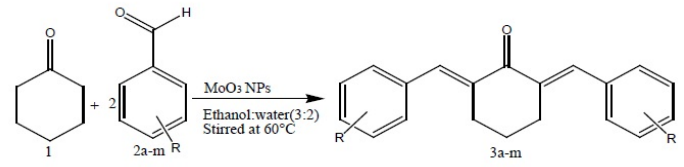

Fig. 1. Scheme 1.

\section{Experimental}

The AR grade tetrapropylammonium bromide (TPAB), tetrahydrofuran (THF) and acetonitrile $(\mathrm{ACN})$ were delivered from Aldrich and S.D. Fine Chemical Supplier and used without any additional preparation. The sacrificial anode in the form of molybdenum sheet and platinum sheet as the inert cathode having thickness of $0.25 \mathrm{~mm}$ and purity of $99.9 \%$ were purchased from Alfa Asaer. The specially designed electrolysis cell with a volume capacity of $30 \mathrm{ml}$ was used.

\subsection{Catalyst preparation}

In the initial experiment we have used a molybdenum metal sheet $(1 \times 1 \mathrm{~cm})$ as the anode and a platinum sheet $(1 \times 1 \mathrm{~cm})$ as the cathode. These two electrodes were placed parallel to one another and separated by $1.0 \mathrm{~cm}$ in $0.01 \mathrm{M}$ solution of TPAB prepared in ACN/THF (4:1), which also served as the supporting electrolyte (Fig. 1). The electrolysis process was then carried out at $14 \mathrm{~mA} / \mathrm{cm}^{2}$ current density for $2.0 \mathrm{~h}$. The colloidal solution thus obtained was kept in air-tight glass bottle to settle for a day. The agglomerated solid sample was separated from the solution by decantation and washed three to four times with THF to remove TPAB The washed samples were then dried under vacuum desiccators and stored in air-tight containers.

\subsection{Characterization}

The prepared molybdenum oxide nanoparticles were characterized by UV-Vis, FT-IR, XRD, TEM and SEM-EDS techniques. The UV-Vis studies were recorded with JASCO 503 spectrophotometer using a quartz cuvette with ACN/THF (4:1) as a reference solvent. The IR spectra were recorded on FT-IR spectrophotometer (JASCO, FT-IR/4100, Japan), using dry $\mathrm{KBr}$ as a standard reference in the range of 400 to $4000 \mathrm{~cm}^{-1}$. The X-ray powder diffraction patterns of the molybdenum oxide nanoparticles were recorded on Bruker $8 \mathrm{D}$ advance $\mathrm{X}$-ray diffractometer using $\mathrm{CuK} \alpha$ radiation of the wavelength $=1.54056 \AA$. The morphology and elemental composition of molybdenum oxide nanoparticles were examined using energy dispersive spectrophotometer (EDS). The SEM analysis was carried out with JEOL, JSM-6330 LA operated at $20.0 \mathrm{kV}$ and $1.0000 \mathrm{nA} .{ }^{1} \mathrm{H}$ NMR and ${ }^{13} \mathrm{C}$ NMR spectra were recorded on a Bruker AvIII HD$300 \mathrm{MHz}$ FT-NMR spectrometer with $\mathrm{CDCl}_{3}$ as a solvent. The chemical shift values were recorded as $\delta$ (ppm units) relative to tetramethylsilane $\left(\mathrm{Me}_{4} \mathrm{Si}\right)$ as an internal standard. Mass spectra were recorded on an Agilent 6520 Q-TOF mass spectrometer for ESI scan.

\subsection{Procedure of the synthesis of 2,6- bis(benzylidene)cyclohexanone}

A mixture of aromatic aldehyde $(10 \mathrm{mmol})$, cyclohexanone $(5 \mathrm{mmol})$ and $\mathrm{MoO}_{3}$ nanoparticles $(60 \mathrm{mg})$ in $5 \mathrm{~mL}$ ethanol:water (3:2) was stirred at 
$60{ }^{\circ} \mathrm{C}$ till the completion of reaction (monitored by TLC). After cooling, the obtained solid product was filtered, washed with water and recrystallized with ethanol to obtain pure product. The hot reaction mixture was centrifuged for recovery of catalyst. The recovered catalyst was washed with ethanol, dried and reused three times in same reaction.

\subsection{Spectral data of the compounds}

2,6-bis(benzylidene)cyclohexanone (3a) Coloryellow crystals MP: 115 to $116^{\circ} \mathrm{C}$.

$\mathrm{IR}(\mathrm{KBr}) \quad \mathrm{V}_{\max } / \mathrm{cm}^{-1}: 3020,2902,1658,1607$, 1573,1486, 970, 750, ${ }^{1} \mathrm{H}-\mathrm{NMR}(300.13 \mathrm{MHz}$, $\left.\mathrm{CDCl}_{3}, \delta \mathrm{ppm}\right): 1.73$ to $1.81\left(\mathrm{~m}, 2 \mathrm{H}, \mathrm{CH}_{2}\right)$, 2.90 to $2.93\left(\mathrm{t}, 4 \mathrm{H}, 2 \mathrm{CH}_{2}\right), 7.24$ to $7.55(\mathrm{~m}$, $10 \mathrm{H}, \quad \mathrm{Ar}-\mathrm{H}), \quad 7.80(\mathrm{~S}, \quad 2 \mathrm{H}, \quad 2=\mathrm{CH}) .{ }^{13} \mathrm{C}-\mathrm{NMR}$ $\left(75.46 \mathrm{MHz}, \mathrm{CDCl}_{3}, \delta \mathrm{ppm}\right): 23.19\left(\mathrm{CH}_{2}\right)$, 28.62 to $29.09\left(2 \mathrm{CH}_{2}\right), \quad 128.08(4 \mathrm{CH}$ of $\mathrm{Ar})$, $128.55(4 \mathrm{CH}$ of $\mathrm{Ar}-\mathrm{H}) 135.80(2 \mathrm{CH}), 136.17(2 \mathrm{C}-$ Ar), $136.38(2 \mathrm{C}=\mathrm{C}), 190.50(\mathrm{C}=\mathrm{O})$. MS $(\mathrm{EI}) \mathrm{m} / \mathrm{z}$ 275( $\left.\mathrm{M}^{+}\right)$.

2,6-bis(p-chlorobenzylidene)cyclohexanone (3b) Color-brown solid; MP: 149 to $151^{\circ} \mathrm{C}$.

$\mathrm{IR}(\mathrm{KBr}) \quad \mathrm{V}_{\text {max }} / \mathrm{cm}^{-1}: \quad 2930,1665,1606,1576$, 1350, $810 \mathrm{~cm}^{-1} .{ }^{1} \mathrm{H}-\mathrm{NMR} \quad(300.13 \mathrm{MHz}$, $\left.\mathrm{CDCl}_{3}, \delta \mathrm{ppm}\right): 1.82$ to $1.88\left(\mathrm{~m}, 2 \mathrm{H}, \mathrm{CH}_{2}\right)$, $2.96\left(\mathrm{t}, 4 \mathrm{H}, 2 \mathrm{CH}_{2}\right), 7.60$ to $8.22(\mathrm{~m}, 8 \mathrm{H} \mathrm{Ar}-\mathrm{H})$, $8.30(\mathrm{~s}, \quad 2 \mathrm{H}, \quad 2=\mathrm{CH}) .{ }^{13} \mathrm{C}-\mathrm{NMR} \quad 26.72\left(\mathrm{CH}_{2}\right)$, $27.46\left(2 \mathrm{CH}_{2}\right), \quad 126.4(4 \quad \mathrm{CH}-\mathrm{Ar}), \quad 128.70(4$ $\mathrm{CH}$ of $\mathrm{Ar}), \quad 135.20(2 \mathrm{C}-\mathrm{Ar}), \quad 137.20(2 \mathrm{C}=\mathrm{C})$, $145.40(2 \mathrm{CH}=\mathrm{C}), 187.20(\mathrm{C}=\mathrm{O})$.

2,6-bis(p-nitrobenzylidene)cyclohexanone (3d) Color-yellow solid; MP: 158 to $160^{\circ} \mathrm{C}$.

$\mathrm{IR}(\mathrm{KBr}) \quad \mathrm{V}_{\max } / \mathrm{cm}^{-1}$ : 3081，2925,1660, 1606, 1575, 1260, $828 \mathrm{~cm}^{-1}$. ${ }^{1} \mathrm{H}-\mathrm{NMR}(300.13 \mathrm{MHz}$, $\left.\mathrm{CDCl}_{3}, \delta \mathrm{ppm}\right): 1.75$ to $1.82\left(\mathrm{~m}, 2 \mathrm{H}, \mathrm{CH}_{2}\right)$, 2.92(t, $\left.4 \mathrm{H}, 2 \mathrm{CH}_{2}\right), 7.35$ to $7.44(\mathrm{~m}, 8 \mathrm{H} \mathrm{Ar}-\mathrm{H})$, $7.72(\mathrm{~s}, \quad 2 \mathrm{H}, \quad 2=\mathrm{CH}) . \quad{ }^{13} \mathrm{C}-\mathrm{NMR} \quad 26.72\left(\mathrm{CH}_{2}\right)$, $27.46\left(2 \mathrm{CH}_{2}\right), \quad 121.10(4 \quad \mathrm{CH}-\mathrm{Ar}), \quad 127.30(4$ $\mathrm{CH}$ of $\mathrm{Ar}), \quad 137.20(2 \mathrm{C}-\mathrm{Ar}), \quad 141.30(2 \mathrm{C}=\mathrm{C})$, 145.40 $(2 \mathrm{CH}=\mathrm{C}), 181.20(\mathrm{C}=\mathrm{O})$.

\section{Results and discussion}

The UV-Vis absorption spectrum recorded for $\mathrm{MoO}_{3}$ nanoparticles exhibits maximum absorption at $634 \mathrm{~nm}$, which can be attributed to the Surface Plasmon Resonance (SPR) peak of molybdenum oxide nanoparticles. A broad peak around $634 \mathrm{~nm}$ can be attributed to a wide size distribution of particles in the solution. The broadening of SPR peak was due to the agglomeration of the nanoparticles in the sample and high width of these particles distribution.

In IR spectrum of $\mathrm{MoO}_{3}$ nanoparticles, broad peaks appear at $3432 \mathrm{~cm}^{-1}$ and $1633 \mathrm{~cm}^{-1}$ due to the stretching and bending vibrations of hydroxyl groups adsorbed on molybdenum oxide nanoparticles. The peak at $949 \mathrm{~cm}^{-1}$ is due to the terminal $\mathrm{Mo}=\mathrm{O}$ bonds, which indicate the layered orthorhombic phase [38] and absorption at $848 \mathrm{~cm}^{-1}$ and $597 \mathrm{~cm}^{-1}$ are of the stretching and bending mode of Mo-O-Mo vibrations. The spectrum also contains distinct peaks at $496 \mathrm{~cm}^{-1}$ and $669 \mathrm{~cm}^{-1}$, which correspond to the mixed phase that contains molybdenum and molybdenum oxide.

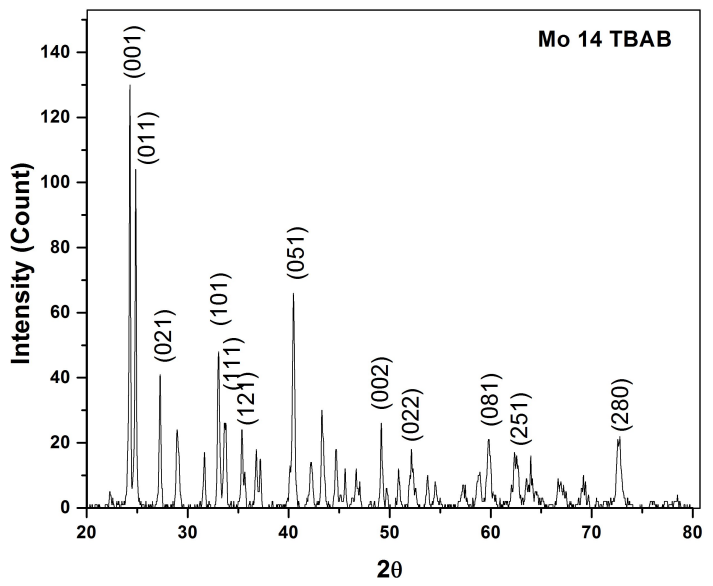

Fig. 2. XRD pattern of $\mathrm{MoO}_{3}$ nanoparticles.

The X-ray diffraction pattern shown in Fig. 2 explains the crystal structure and phase composition of $\mathrm{MoO}_{3}$ nanocrystalline materials. The sharp diffraction peaks at (021), (101), (001), (011), (111), (121), (051) and (002) indicate crystalline nature of $\mathrm{MoO}_{3}$ nanomaterials with orthorhombic lattice system, having lattice 
parameters $\mathrm{a}=3.966 \AA, \mathrm{b}=13.82 \AA, \mathrm{c}=3.703 \AA$ (JCPDS: 05-0506) and strong peaks show crystalline nature of $\mathrm{MoO}_{3}$ nanoparticles.

The morphology of the product was examined by scanning electron microscope. Fig. 3a reveals that the sample has ununiform crystals, which show square- and cubic-like structures. The quantitative and qualitative analysis was carried out on the basis of EDS spectra and the elemental composition of $\mathrm{MoO}_{3}$ nanoparticles is shown in Fig. 3b. The Mo and $\mathrm{O}$ peaks can be obviously found in the spectra but lack of any other peaks indicates that the sample is composed of pure $\mathrm{MoO}_{3}$ nanoparticles.
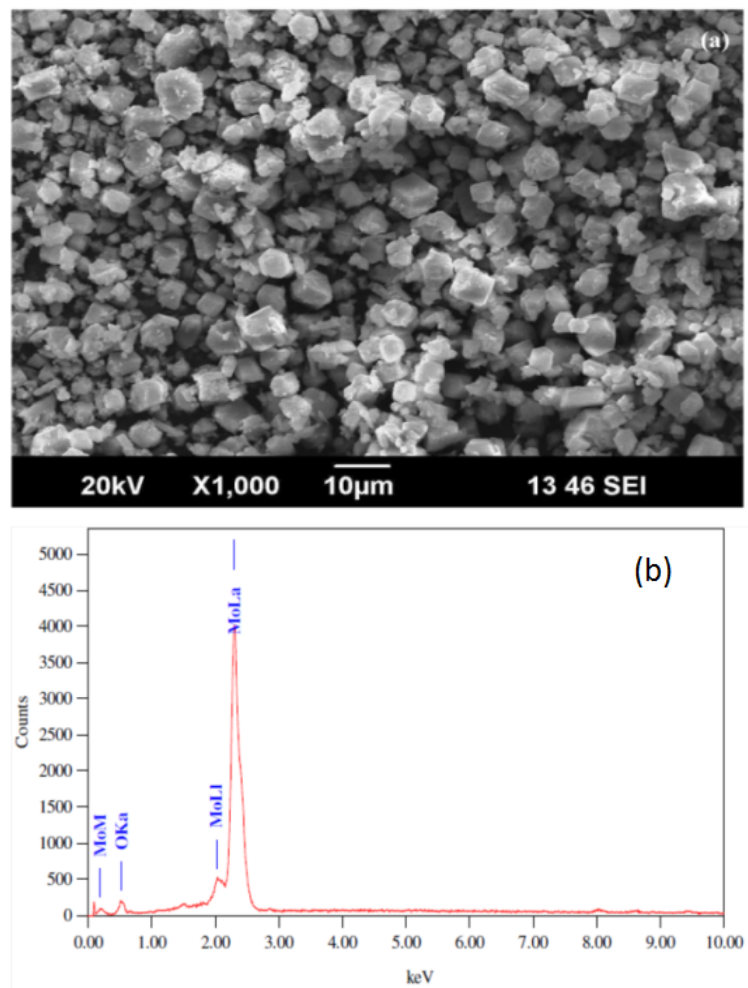

Fig. 3. (a) SEM micrograph; (b) EDS plot of $\mathrm{MoO}_{3}$ nanoparticles.

\subsection{Catalytic activity of $\mathrm{MoO}_{3}$ nanoparticles}

We have revealed herein for the first time, that the $\mathrm{MoO}_{3}$ nanoparticles catalyzed aldol condensation of cyclohexanone with a variety of aldehydes by simple stirring at $60{ }^{\circ} \mathrm{C}$. In the present work, an attempt has been made to optimize the reaction conditions by using 4 nitro-benzaldehyde and cyclohexanone as a model reaction at different solvents and amounts of catalyst used. From Table 1 it can be seen that the best amount of $\mathrm{MoO}_{3}$ nanoparticles in the starting material is $60 \mathrm{mg}$. There is a considerable increase in the yield of product when the concentration of $\mathrm{MoO}_{3}$ nanoparticles increases from $10 \mathrm{mg}$ to $60 \mathrm{mg}$. But when we increased catalyst quantity to $70 \mathrm{mg}$ there was no considerable change in reaction time and yield of the product.

Table 1. Screening of catalyst $\left(\mathrm{MoO}_{3}\right)$ concentration for the synthesis of $3 \mathrm{~d}$.

\begin{tabular}{cccc}
\hline Entry & $\begin{array}{c}\text { Catalyst } \\
\text { amount }(\mathrm{mg})\end{array}$ & $\begin{array}{c}\text { Time } \\
(\mathrm{min})\end{array}$ & Yield $^{\mathrm{a}}(\%)$ \\
\hline \hline 1 & 10 & 240 & Trace \\
2 & 20 & 160 & 36 \\
3 & 40 & 120 & 66 \\
4 & 50 & 90 & 92 \\
5 & 60 & 90 & 94 \\
6 & 70 & 90 & 95 \\
\hline \multicolumn{4}{c}{ isolated yield }
\end{tabular}

Table 2. Optimization of solvent in the aldol condensation of cyclohexanone and 4nitrobenzaldehyde with $60 \mathrm{mg} \quad \mathrm{MoO}_{3}$ nanoparticles as catalyst.

\begin{tabular}{cccc}
\hline Entry & Solvent & Time (h) & Yield $^{\mathrm{a}}(\%)$ \\
\hline \hline 1 & ACN & 3 & 54 \\
1 & Toluene & 3 & 32 \\
2 & THF & 3 & 35 \\
4 & Methanol & 3 & 62 \\
5 & Ethanol & 3 & 76 \\
6 & Ethanol:water (3:2) & 2 & 94 \\
\hline \multicolumn{4}{c}{ aisolated yield }
\end{tabular}

In this study, the effect of different solvents was investigated and given in Table 2. The choice of a solvent proved critical. We observed that polar solvents, such as methanol, ethanol, acetonitrile, offerred better yield than nonpolar ones and the mixture of water $(2 \mathrm{~mL})$ and ethanol $(3 \mathrm{~mL})$ was most effective solvent offerring maximum yield of the product. 
Table 3. Synthesis of 2,6-bis(benzylidene)cyclohexanone using $\mathrm{MoO}_{3} \mathrm{NPs}$ catalyst under ethanol:water ratio (3:2).

\begin{tabular}{cccccc}
\hline \multirow{2}{*}{ Products $^{\mathrm{a}}$} & \multirow{2}{*}{$\mathrm{R}$} & \multirow{2}{*}{ Time $(\mathrm{min})$} & \multirow{2}{*}{ Yield $^{\mathrm{b}}(\%)$} & \multicolumn{2}{c}{ Melting point $\left({ }^{\circ} \mathrm{C}\right)$} \\
\hline \hline $3 \mathrm{a}$ & $\mathrm{H}$ & 120 & 91 & $115-116115-118[14]$ \\
$3 \mathrm{~b}$ & $4-\mathrm{Cl}$ & 95 & 95 & $145-147147-148[14]$ \\
$3 \mathrm{c}$ & $2-\mathrm{Cl}$ & 130 & 92 & $103-105102-106[23]$ \\
$3 \mathrm{~d}$ & $4-\mathrm{NO}_{2}$ & 90 & $94^{\mathrm{b}}, 91^{\mathrm{c}}, 89^{\mathrm{c}}, 84^{\mathrm{c}}$ & $158-160160-163[14]$ \\
$3 \mathrm{e}$ & $3-\mathrm{NO}_{2}$ & 130 & 95 & $191-192188-190[21]$ \\
$3 \mathrm{f}$ & $4-\mathrm{CH}_{3}$ & 100 & 90 & $160-162170-171[14]$ \\
$3 \mathrm{~g}$ & $2,4-\mathrm{Cl} l_{2}$ & 140 & 89 & $166-167163-164[16]$ \\
$3 \mathrm{~h}$ & $4-\mathrm{OMe}$ & 95 & 93 & $160-161161-163[20]$ \\
$3 \mathrm{i}$ & $4-\mathrm{OH}$ & 100 & 94 & $172-174$ & - \\
$3 \mathrm{j}$ & $4-\mathrm{F}$ & 105 & 94 & $156-157156-158[17]$ \\
$3 \mathrm{k}$ & $4-\mathrm{Br}$ & 110 & 92 & $162-163163-165[23]$ \\
31 & $2-f u r f u r a l d e$ & 145 & 85 & $140-142140-142[21]$ \\
$3 \mathrm{~m}$ & Cinnamalde & 130 & 88 & $180-181$ & $180[14]$ \\
\hline
\end{tabular}

${ }^{a}$ Reaction condition: aldehyde $(2 \mathrm{mmol})$, cyclohexanone $(1 \mathrm{mmol})$, and $60 \mathrm{mg}$ of $\mathrm{MoO}_{3}$ nanoparticles stirred at $60{ }^{\circ} \mathrm{C}$, ${ }^{\text {b }}$ isolated yield, ${ }^{c}$ isolated yield reused of catalyst $1^{\text {st }}, 2^{\text {nd }}$ and $3^{\text {rd }}$ cycle, respectively.

Table 4. Comparison of the results for $\mathrm{MoO}_{3}$ nanoparticles with other catalysts reported in the literature.

\begin{tabular}{ccccc}
\hline Sr. No. & Catalyst & Reaction condition/time in h & Yield (\%) & Literature \\
\hline \hline 1 & $\mathrm{RuCl}_{3}$ & $120{ }^{\circ} \mathrm{C}$ sealed $/ 12$ & 94 & 14 \\
2 & $\mathrm{KOH}$ & $0{ }^{\circ} \mathrm{C}$ ethanol RT/4 & 90 & 16 \\
3 & $\mathrm{I}_{2}$ & $\mathrm{CH}_{2} \mathrm{Cl}_{2} \mathrm{RT} / 4.5$ & 92 & 18 \\
4 & $\mathrm{Yb}(\mathrm{OTf})_{3}$ & Flourous solvent $120^{\circ} \mathrm{C} / 12$ & 95 & 20 \\
5 & $\mathrm{Cu}(\mathrm{OTf})_{2}$ & Solvent free $80{ }^{\circ} \mathrm{C} / 6$ & 94 & 21 \\
6 & $\mathrm{NaOAc} / \mathrm{HOAc}$ & $120{ }^{\circ} \mathrm{C} / 7$ & 86 & 22 \\
7 & $\mathrm{MoO}_{3}$ nanoparticles & Ethanol:water $(3: 2) 60^{\circ} \mathrm{C} / 1.5$ & 94 & Present work \\
\hline
\end{tabular}

After optimizing the conditions, the generality of this method was examined by the reaction of cyclohexanone with several aldehydes bearing electron withdrawing groups (such as nitro, chloro, bromo, fluoro, and hydroxyl) and electron donating groups (such as methyl, methoxy). The entire product reacted in a similar manner producing moderate to good yield of expected product. The parasubstituted aromatic aldehyde reacted in a shorter reaction time as compared with ortho and meta substituted aromatic aldehyde in Table 3.

In this study, the catalyst was recovered and reused. The catalyst was recovered by a simple work-up using centrifugation, and then it was washed with ethanol and reused. The catalyst was removed in excellent yields and was used in mentioned reaction for three times; the observation revealed that as the number of recycling of the catalyst increases the activity decreases (Table 4).

Table 4 shows a comparison of the results of our work with the other reported procedures. There are the results of the synthesis of 2,6bis(benzylidene)cyclohexanone derivatives in the presence of different reported catalyst with respect to time and yield of the product. These results show that our catalyst, $\mathrm{MoO}_{3}$ nanoparticles, is more stable in air and nontoxic. It ensures good yield in a short reaction time. 


\section{Conclusions}

$\mathrm{MoO}_{3}$ nanoparticles are inexpensive and efficient reusable catalyst for the synthesis of 2,6-bis(benzylidene)cyclohexanone derivatives. The advantages offered by this method are simple workup, short reaction times, ease of product isolation and high yields. We believe that this method is a useful addition to the present methodology for the synthesis of 2,6bis(benzylidene)cyclohexanone.

\section{Acknowledgements}

The Department of Chemistry acknowledges the financial assistance by UGC-SAP-DRS Scheme-1. We acknowledge the analysis of SEM \& EDS from STIC Cochin. One of the authors (ASR) is thankful for financial assistance from Major Research project [F. No. 832/2010(SR)], University Grants Commission, New Delhi, India.

\section{References}

[1] ReEves R.L, Condensations leading to double bonds, in: S. PATAI (Ed.), in: Chemistry of Carbonyl Group, Wiley Interscience, New York, 1966, p. 567.

[2] Robinson T.P., Ehlers T., Hubbard R.B., Bai X., Arbiser J.L., Goldsmith D.J., Bowena J.P., Bioorg. Med. Chem. Lett., 13 (2003), 115.

[3] Dimmock J.R., Padmanilayam M.P., Zello G.A., Nienaber K.H., Allen T.M., Santos C.L., DE ClercQ E., Balzarini J., Manavathu E.K., StABLES J. P., Eur. J. Med. Chem., 38 (2003), 169.

[4] Piantadosi C., Hall I.H., Irvine J.L., Carlson G.L., J. Med. Chem., 16 (1973), 770.

[5] Kawamata J., Inoue K., Inabe T., Kiguchi M., Kato M., Taniguchi Y., Chem. Phys. Lett., 249 (1996), 29

[6] Deli J., Lorand J., Szabo D., Foldesi A., Pharmazie, 39 (1984), 539.

[7] Ogawa M., Ishili Y., NaKano T., IrIFune S., Jpn. Kohai Tokkyo JP 63192446 A2, in: Chem. Abstr., 63 (1988), 238034.

[8] Xiaofang L., Xianyong Y., Yaqing F., Chinese J. Chem., 27 (2009), 1531.

[9] Kaushal G.K., Polymer, 36 (1995), 1903.

[10] Artico M., Santo R.D., Costi R., Novellino E., Greco G., Massa S., Tramontano E., Marogiu M.F., Montis A.D., Colla P.L., J. Med. Chem., 41 (1998), 3948.

[11] Sinisterra J.V., Garcia-Raso A., J. Syn. Org. Chem., (1984), 502.

[12] Hathaway B.A., J. Chem. Edu., 64 (1987), 367.

[13] Irie K., Watanabe K., B. Chem. Soc. Jpn., 53 (1980), 1366.

[14] Zheng M, Wang L, Shao J, Zhong Q., Synthetic Commun., 27 (1997), 351.
[15] YadaV J.S., Reddy B.V.S., NAGaraju A., SARma J.A.R.P., Synthetic Commun., 32 (2002), 893.

[16] Mahdavinia G.H., Mirzazadeh M., E-J. Chem., 9 (1) (2012), 49.

[17] Ziani N., Lamara K., Sid A., Willem Q., DasSonneville B., Demoneceau A., Eur. J. Chem., 4 (2) (2012), 176.

[18] DAs B., Thirupathi P., Mahender I., Reddy K.R., J. Mol. Catal. A-Chem., 247 (2006), 182.

[19] Salehi P., Dabiri M., Zolfigol M.A., Bodaghi FARD M.A., J. Brazil. Chem. Soc., 15 (2004), 773.

[20] Wang L.M., Sheng J., Tian H., Han J.W., Fan Z.Y., QIan C., J. Syn. Org. Chem, 18 (2004) 3060.

[21] Jianjun L., Weike S., Ning L., Synthetic Commun., 35 (2005), 3037.

[22] Zhou J.F., Sun X.J., Zhu F.X., Li Y.L., Gong G.X., Synthetic Commun., 38 (2008), 4182.

[23] Amoozadeh A., Rahmani S., Nemati F., S. Afr. J. Chem.-S.-Afr. T., 63 (2010), 72.

[24] GiriJa D., Halehatty Bhojyanaik S., VinaykUMar B., Sudhamani C.N., J. Am. Chem. Soc., 1 (3) (2011), 97.

[25] Babu G., Perumal P.T., Synthetic Commun., 27 (1997), 3677

[26] Li J., Yang W., Chen G., Li T., Synthetic Commun., 33 (2003), 2619.

[27] PARviz D., Kazemeini M., Rashid A.M., JozAni K.J., J. Nanopart. Res., 12 (2010), 1509.

[28] Shi Y., Guo B., Corr S.A., Shi Q., Hu Y.S., HeIER K.R., Chen L., Seshadri R., Stucky G.D., Nano Lett., 9 (12) (2009), 4215.

[29] Zhao Y., LiU J., Zhou Y., Zhang Z., Xu Y., Naramoto H., Yamamoto S., J. Phys.-Condens. Mat., 15 (2003), 547.

[30] CHEN D., J. Mater. Chem., 21 (2011), 9332.

[31] Wang F., UEDA W., Chem. Commn., 27 (2008), 3196.

[32] WANG F., UEDA W., Chem.-Eur. J., 15(2009), 742.

[33] Pichat P., Mozzanega M., Hong-Van C., J. Phys. Chem., 92 (1988), 464.

[34] Chen J., Yang H., Cheng L., Front. Phys. China, 1 (2007), 92.

[35] Jadhav S., Nimase M., Gaikwad S., Rajbhoj A., Indian J. Chem. B, 7(4) (2011).

[36] Anandgaonker P., Kulkarni G., Gaikwad S., Rajbhoj A., Chinese J. Catal., 35 (2014), 196.

[37] Anandgaonker P., JadhaV S., Gaikwad S., RaJBHOJ A., J. Clust. Sci., (2014), DOI 10.1007/s10876013-0626-8.

[38] Mai L., Hu B., Chen W., Qi Y., LaO C., YAnd R., DaI Y., WANG Z., Adv. Mater, 19 (2007), 3712.

Received 2014-08-07 Accepted 2014-12-09 